\title{
COMMENTARY/
}

\section{SOUND SPECULATIONS}

\author{
by Bernard Dixon
}

$\mathrm{T}$ oo speculative" was one description applied by New England Journal of Medicine editor Franz J. Ingelfinger to a paper he turned down in August 1968. It was written by W. French Anderson, then newly arrived at the U.S. National Institutes of Health in Bethesda, Maryland. Although Ingelfinger personally felt that the paper was "very erudite and fascinating," duller members of the editorial board won the day and precipitated the rejection letter. Thus were the journal's readers denied access to Anderson's wild ideas. These included a suggestion that the discoveries which had emerged from molecular biology during the 1960 s could be applied to the conquest of genetically based disease, and a proposal that viruses might be harnessed as vectors to carry genetic information into host cells.

Now chief of molecular biology at the National Heart, Lung, and Blood Institute, Anderson is criticised from time to time for grabbing headlines and jumping guns. Nevertheless, it is a measure of both his prescience and the practical progress that has occurred over the past 20 years that the NEJM's decision to refuse the paper can now be pigeon-holed as one of the greatest idiocies in the whole of modern science. Ironically, the very same journal has in recent months published results from Anderson and his colleagues in using retroviral transduction of genes into tumor-infiltrating lymphocytes for the treatment of patients with advanced melanoma.

As I see it, the real mark of maturity in the translation of Anderson's ideas from science fiction into science fact is the degree to which genetic intervention is now being seen as a viable approach to conditions other than genetic diseases. When the history of these times comes to be written, however, this extension of an already revolutionary set of ideas will be seen to have arisen in part from technical failures in the original strategy. Genetic engineers have, for example, found it very much more difficult than they originally imagined to deal with sickle cell anemia and other haemoglobinopathies by inserting therapeutic bits of DNA into bone marrow stem cells. Likewise, there is now less confidence about combatting the single gene defect adenosine deaminase (ADA) deficiency by replacing the faulty gene.

What is new on the agenda, of course, is the alternative approach of giving children with this condition lymphocytes into which normal ADA-producing genes have been incorporated. And if a missing enzyme can be provided in this way, then why not deliver alpha- 1 antitrypsin to emphysema patients by spraying lymphocytes carrying the appropriate gene into their airways? Anderson's colleague Ronald G. Crystal certainly believes this can be done. Countless other possibilities suggest themselves.

Most exciting of all is the notion of "genetic antibiotics." These would be drugs, produced inside cells according to instructions encoded in artificially inserted DNA, that would thwart potentially lethal virus infections. They would not be synthesised continuously, like ADA and other therapeutic proteins, but only in response to infection. The vector responsible for a genetic antibiotic should, therefore, contain two elements-a gene coding for drug production, and a fragment of DNA ensuring that manufacture was induced only under appropriate conditions. The drug could be either a cytocidal toxin, killing the cell and thus forestalling the release of new virus particles, or an agent that interferes with virus replication in more subtle ways. The cis-acting DNA sequence regulating expression of the drug gene, normally quiescent in the cell, should ensure that it was switched on as a consequence of virus infection.

Perspectives in Biology and Medicine is clearly a journal whose editor (Richard L. Landau) and Advisory Board (including Francis Crick) are free of the timorous caution that constrained the NEJM in 1968. In the current issue, they have permitted Mark A. Goldsmith of Brigham and Women's Hospital (Boston, MA) to put forward two specific proposals to flesh out the speculative idea of genetic antibiotics.

First, there is the prospect of poising such an agent to thwart the autoamplification of human immunodeficiency virus (HIV) particles that can take place suddenly after the virus has remained latent inside an individual's $T$ cells for many years. A key component of this process is the transactivation of viral gene expression through the tat protein (encoded by HIV itself) and its cis-acting stretch of nucleotides within the long terminal repeats (LTR) flanking the integrated provirus. So the spread of HIV might be impaired by a genetic antibiotic consisting of a "suicide toxin" linked to an abbreviated LTR segment. As soon as virus replication was initiated, the tat protein would trigger expression of the toxin, wrecking the cell and thwarting virus assembly. Goldsmith argues that such a weapon might prove effective not only in preventing disease in HIVpositive individuals but also in arresting virus spread in patients already developing AIDS.

Adult $\mathrm{T}$ cell leukemia offers a similar scenario. It is thought to be caused by human lymphocytotrophic virus 1 (HTLV-1), whose expression is regulated by a system of transactivation similar to that of HIV. Leukaemic cells show persistent expression of certain cellular genes that have fallen under the influence of the viral tat protein. Perhaps, therefore, a toxin gene linked to a derivative of the HTLV1 LTR could selectively eliminate the cancer cells following universal transformation of the $\mathrm{T}$ lymphocytes. Such a genetic antibiotic would cause the exclusive deletion of the cells expressing the viral gene transregulators.

It's a brave idea-albeit with technical challenges (such as achieving high rates of gene transfer) yet to be surmounted. But in light of the advances of the past two decades, it seems far from inappropriate for Goldsmith to argue: "The time is right for us to be broad in our imagination." 